\title{
Leucocytes in adult burrowing parrots Cyanoliseus patagonus in the wild: variation between contrasting breeding seasons, gender, and individual condition
}

\author{
Andreas Plischke • Petra Quillfeldt • \\ Thomas Lubjuhn · Santiago Merino • \\ Juan F. Masello
}

Received: 20 February 2009/Revised: 7 September 2009/Accepted: 21 September 2009/Published online: 11 October 2009

(C) The Author(s) 2009. This article is published with open access at Springerlink.com

\begin{abstract}
Wild birds exposed to stressors may modulate their investment in immunity. We studied the leucocytes of breeding burrowing parrots (Cyanoliseus patagonus) in Patagonia during five breeding seasons, during which global climate events such as a strong La Niña and a weak El Niño occurred. We observed strong inter-annual variation in the ratio of heterophils to lymphocytes $(H / L)$, with higher $H / L$ during the adverse conditions of La Niña compared with the favourable conditions of El Niño for the studied region. Nevertheless, highest $H / L$ were found in the breeding season following a La Niña event; this is probably explained by a combination of long-term detrimental effects of climatic conditions and other, e.g. biotic, stressors. Males had higher $H / L$ than females, and $H / L$ ratios were negatively related to individual body condition.
\end{abstract}

Keywords Body condition - Blood cell counts . Climatic conditions $\cdot$ El Niño southern oscillation (ENSO) . $H / L$ ratio $\cdot$ Psittaciformes $\cdot$ Sex differences

Communicated by P. H. Becker.

A. Plischke · P. Quillfeldt · J. F. Masello ( ()

Max Planck Institute for Ornithology, Vogelwarte Radolfzell,

Schlossallee 2, 78315 Radolfzell, Germany

e-mail: masello@orn.mpg.de

T. Lubjuhn

Institute for Evolutionary Biology and Ecology,

Rheinische Friedrich-Wilhelms-Universität Bonn,

Bonn, Germany

S. Merino

Departamento de Ecología Evolutiva,

Museo Nacional de Ciencias Naturales, CSIC,

28006 Madrid, Spain

\section{Introduction}

Environmental stressors and their effects on individual growth, reproduction and pathogen defence are important issues in ecological research and conservation biology. In this context, quantification of white blood cells (leucocytes) has become a useful tool in behavioural ecology. In particular, the ratio of two types of leucocytes, the heterophils and lymphocytes ( $H / L$ ratio), has been used as an indicator of stress in birds (reviewed by Davis et al. 2008).

In response to exposure to various stressors, the relative number of heterophils (phagocyting cells of the innate immune system) in peripheral blood increases while the relative number of lymphocytes (part of the acquired immune system) decreases (Gross and Siegel 1983; Maxwell 1993). These effects, mediated by glucocorticoids (mainly corticosterone in birds), are seen in all five vertebrate taxa in response to either natural stressors or exogenous administration of stress hormones (Siegel 1985; see also Davis et al. 2008). Therefore, high $H / L$ ratios in blood samples can reliably indicate high glucocorticoid levels and provide a reliable assessment of stress in all vertebrate taxa (Davis et al. 2008). Obtaining $H / L$ ratios from blood smears has important advantages compared with hormone assays:

1. $H / L$ ratios are not influenced by handling times up to $1 \mathrm{~h}$ (Davis 2005);

2. the method can easily be added to standard sampling procedures in the field, as very small amounts of blood are needed; and

3 . counting leucocytes from blood smears is an inexpensive and repeatable method (Davis et al. 2008).

Baseline information on leucocyte profiles from wild birds is scarce (but see, e.g., Merino et al. 1999; Vleck 
et al. 2000; Garamszegi et al. 2006; Owen and Moore 2006; Quillfeldt et al. 2008). In Psittaciformes, haematology values, with a few exceptions (Joyner et al. 1992; Karesh et al. 1997; Sheridan et al. 2004; Deem et al. 2005; Low et al. 2006; Tompkins et al. 2006; Masello et al. 2009), are those of captive birds (see Masello et al. 2009 and references therein). Captivity, however, has been shown to affect avian leucocyte counts significantly (Ewenson et al. 2001).

An important source of environmental stress affecting wild birds in South America is the El Niño southern oscillation (ENSO). El Niño (warm) episodes are usually associated with excess of rain in some parts of the globe and a deficit of rain in others (Ropelewski and Halpert 1987). El Niño episodes (of ENSO) are often followed by La Niña (cold) episodes, which roughly produce climate patterns opposite to those observed during El Niño. In southern South America, La Niña is associated mostly with droughts, affecting primary productivity and crop production (Masello and Quillfeldt 2004 and references therein). Little information is available on the effects of ENSO on bird species in this region (but see Masello and Quillfeldt 2004 and references therein). Also poor is our understanding of the effects of ENSO on Psittaciformes (but see Masello and Quillfeldt 2004; Renton and Salinas-Melgoza 2004). As Psittaciformes have become one of the most endangered orders of birds (Snyder et al. 2000), a good understanding of the effects of climate events on the condition of birds is needed for identification of key risks and for management and conservation of endangered populations of parrots.

Burrowing parrots Cyanoliseus patagonus are colonial Psittaciformes that, in Argentina, mainly inhabit the phytogeographical province of "Monte", semi-desert scrubland characterized by bushy steppes and xerophytes forests. These parrots need sandstone, limestone, or earth cliffs to excavate nest burrows, where they breed once a year (September to January; Masello and Quillfeldt 2004 and references therein). Previous studies have shown that ENSO dramatically affects nestling survival and growth, and breeding success of burrowing parrots (Masello and Quillfeldt 2004, 2008). Until now, haematological information about this species was only available from nestlings in the wild (Masello et al. 2009) or from captive adults (Polo et al. 1998).

In this study, ecological aspects of leucocyte values in adult burrowing parrots were investigated during five breeding seasons. During our study, the region of Northeastern Patagonia, Argentina, was affected by a severe drought associated with a La Niña event in 1998-1999, and by a weak El Niño in 2004-2005. On the basis of the stressrelatedness of leucocyte values and the $H / L$ ratio in particular, we predicted that:
1. $H / L$ ratios would be elevated during La Niña compared with El Niño years; and

2. $H / L$ ratios would be negatively correlated with individual body condition.

\section{Materials and methods}

The study was carried out during five breeding seasons (1998 = breeding season from Oct. 1998 to Feb. 1999; $1999=$ Nov. 1999 to Jan. 2000; $2001=$ Nov. 2001 to Jan. 2002; 2003 = Nov. 2003 to Jan. 2004; $2004=$ Nov. 2004 to Jan. 2005), at the largest colony of burrowing parrots located in El Cóndor, North-eastern Patagonia, Argentina (Masello et al. 2009 and references therein). In this region, precipitation is the main factor limiting primary production (Paruelo et al. 1998). The breeding seasons studied were characterized by very contrasting weather conditions and, hence, contrasting breeding success (Masello and Quillfeldt 2004). The 1998 breeding season was subject to highly unfavourable environmental conditions (very low precipitation), associated with the La Niña phase of ENSO, that strongly reduced breeding success (Masello and Quillfeldt 2004, 2008), whereas during the 2004 breeding season favourable El Niño conditions (increased precipitation) prevailed in the study region (Masello and Quillfeldt 2008).

According to accessibility, a sector of the colony was selected for monitoring and sampling, as part of an ongoing study on the behavioural ecology of this species (Masello et al. 2009 and references therein). Nests were inspected every five days by climbing the cliff face. Adult burrowing parrots were captured while attending their nestlings. Four morphometric characteristics of adults were recorded:

1. body mass (using a digital balance, to the nearest $1 \mathrm{~g}$ ); 2. tarsus length;

3. bill length (using callipers, to the nearest $0.1 \mathrm{~mm}$ ); and

4. wing length (distance from anterior surface of the radio-carpal joint to the tip of the longest primary, flattened along a wing rule to the nearest $1 \mathrm{~mm}$ ).

Blood samples of burrowing parrots were taken by puncture of the cutaneous ulnar vein, using a hypodermic needle and heparinised capillary tubes, immediately after capture, i.e. between 11 am and $7 \mathrm{pm}$. Every individual was sampled once. As previously described (Masello et al. 2009 and references therein), molecular sex determination was carried out using PCR amplification of a highly conserved $\mathrm{W}$-linked gene. Blind duplicate and triplicate blood samples of burrowing parrots were analysed in order to ensure the accuracy of gender determination. In all cases duplicates and triplicates confirmed the results. Blood sampling 
had no detectable adverse effects on the birds. After measurement and sampling, the birds were released in their burrows. No desertion occurred.

One drop of blood was smeared then air dried on a glass slide immediately after sampling, and fixed with absolute methanol later in the laboratory. All smears were stained with Giemsa. Following previous studies (Merino et al. 1999; Masello et al. 2009), differential leucocyte counts were carried out with a light microscope $(1000 \times$ magnification with oil immersion) in parts of the smear where erythrocytes had separated in a monolayer. As in Merino et al. (1999) the samples were crossed from down to up to minimize differences in the thickness of the blood smear. Heterophils, eosinophils, basophils, lymphocytes, and monocytes were counted following Dein (1986) and Hawkey and Dennett (1989). A total of 100 leucocytes were counted in each smear, thereby obtaining percentages of the different types of leucocytes and the $H / L$ ratio. Furthermore, the corresponding number of erythrocytes that were scanned in order to detect 100 leucocytes was used to calculate the relative abundances of leucocyte types per 10,000 erythrocytes. Counting leucocytes and the corresponding erythrocytes took approximately $15 \mathrm{~min}$ per smear. In total, blood smears of 138 male and female adult burrowing parrots obtained in five breeding seasons were analysed (1998: 22 male and 24 females; 1999: 8 males and 10 females; 2001: 9 males and 7 females; 2003: 21 males and 21 females; 2004: 8 males and 8 females). Because of the absence or very low numbers of monocytes, basophils, and eosinophils in most of the blood smears, only $H / L$ ratios, heterophils per 10,000 erythrocytes, lymphocytes per 10,000 erythrocytes, and total relative abundance of leucocytes per 10,000 erythrocytes were considered in further statistical analyses. The $H / L$ ratio has shown a low measurement error under field conditions (Gross and Siegel 1983; Maxwell 1993; Merino et al. 1999; see also review by Davis et al. 2008). Following Lessells and Boag (1987), we calculated intra-observer repeatability. Our results suggested reasonable repeatability by the same observer $(r=0.72$, ANOVA, $F=6.18, d f 23, P=0.002$; the difference was below 0.08 for 10 out of 12 cases). All birds were sampled within $30 \mathrm{~min}$ of capture to ensure that the $H / L$ ratios did not change by routine handling (Davis 2005).

Following previous studies (Masello et al. 2009 and references therein), and because body mass is partly the result of structural body size and does not necessarily reflect the quantity of body reserves, body mass was scaled to body size as a condition index. To determine body condition, multiple linear regression of body mass as dependent variable with wing, tarsus, and bill length as predictors was carried out $(n=91, R=0.465, F=7.999$, $P<0.001)$. This allowed us to calculate an expected body mass for each combination of the three size factors as follows: expected body mass $=0.84$ (wing length) + 7.77(tarsus length) +1.64 (bill length) -205.34 . Then, body condition was calculated as the ratio between observed body mass and expected body mass. Body condition was calculated for 66 males (of a total of 68 sampled individuals) and 69 females (of a total of 70 individuals). This was because of lack of precise bill measurements for some individuals with broken bill tips.

Data were analysed using Sigma Stat 2.03 and SPSS 11.0. General linear models (GLMs), based on Type III sums of squares, were fitted to the data. Separate models were fitted for " $H / L$ ratio", "heterophils/10.000 erythrocytes", "lymphocytes/10.000 erythrocytes", and "total leucocytes/10.000 erythrocytes" as response variables. Each model was initially calculated with "year" and "sex" as categorical predictors and "body condition", "sampling day" (range $=16-72$ ), and "days after hatching of first chick" (range $=1-66$, an estimate of brood age) as continuous predictor variables. Non-significant explanatory variables or interaction terms (all $P>0.2$ ) were deleted from initially saturated models in a stepwise manner and only reduced models are shown. The covariates "sampling day" and "days after hatching of first chick" were nonsignificant in all analyses. When linear models showed signs of non-normality of error terms or heteroscedasticity, explanatory and response variables were transformed using natural logarithm $(l n)$ transformations. As a measure of effect size partial Eta-squared values $\left(\eta^{2}\right)$ were included, i.e. the proportion of the effect + error variance that is attributable to the effect. The sums of the $\eta^{2}$ values are not additive (e.g. http://web.uccs.edu/lbecker/SPSS/glm effectsize.htm). All presented means are estimated marginal means obtained from the fitted linear models (adjusted for the covariate). Bonferroni correction was applied to multiple comparisons of estimated marginal means. Throughout this study the significance level used is $P<0.05$.

\section{Results}

Mean values of the differential leucocyte counts of 138 adult burrowing parrots obtained during the five breeding periods studied are shown in Table 1 . In both males and females, the highest relative counts were obtained for heterophils, followed by lymphocytes. Relative numbers of monocytes and eosinophils were extremely low, and no basophils were detected (Table 1).

Mean $H / L$ ratios were significantly higher in 1998 and 1999 than in 2003 and 2004, with intermediate values in 2001 (Fig. 1). This pattern of yearly variation was similar for males and females. Male burrowing parrots had higher 
Table 1 Mean values of leucocyte counts of adult burrowing parrots in NE Patagonia, Argentina

\begin{tabular}{|c|c|c|c|c|}
\hline & \multicolumn{2}{|l|}{$\begin{array}{l}\text { Males } \\
n=68\end{array}$} & \multicolumn{2}{|l|}{$\begin{array}{l}\text { Females } \\
n=70\end{array}$} \\
\hline & Mean $\pm \mathrm{SE}$ & Range & Mean $\pm \mathrm{SE}$ & Range \\
\hline Heterophils (\%) & $76.6 \pm 1.7$ & $32.0-96.0$ & $71.6 \pm 1.5$ & $43.0-94.0$ \\
\hline Lymphocytes (\%) & $21.5 \pm 1.6$ & $4.0-68.0$ & $25.8 \pm 1.5$ & $6.0-57.0$ \\
\hline Eosinophils (\%) & $1.4 \pm 0.2$ & $0.0-7.0$ & $2.3 \pm 0.3$ & $0.0-13.0$ \\
\hline Monocytes (\%) & $0.4 \pm 0.1$ & $0.0-4.0$ & $0.3 \pm 0.1$ & $0.0-4.0$ \\
\hline$H / L$ ratio & $6.1 \pm 0.7$ & $0.5-24.0$ & $4.3 \pm 0.4$ & $0.8-15.7$ \\
\hline Heterophils/10,000 erythrocytes & $21.5 \pm 1.6$ & $4.1-65.8$ & $21.1 \pm 1.5$ & $4.6-72.7$ \\
\hline Lymphocytes/10,000 erythrocytes & $5.7 \pm 0.7$ & $1.0-38.4$ & $7.3 \pm 0.6$ & $0.6-28.5$ \\
\hline Eosinophils/10,000 erythrocytes & $0.4 \pm 0.1$ & $0.0-2.6$ & $0.6 \pm 0.1$ & $0.0-4.6$ \\
\hline Monocytes/10,000 erythrocytes & $0.1 \pm 0.0$ & $0.0-0.9$ & $0.1 \pm 0.0$ & $0.0-0.9$ \\
\hline Total leucocytes/10,000 erythrocytes & $27.6 \pm 1.8$ & $7.8-77.4$ & $29.1 \pm 1.9$ & $5.8-92.1$ \\
\hline
\end{tabular}

(a)
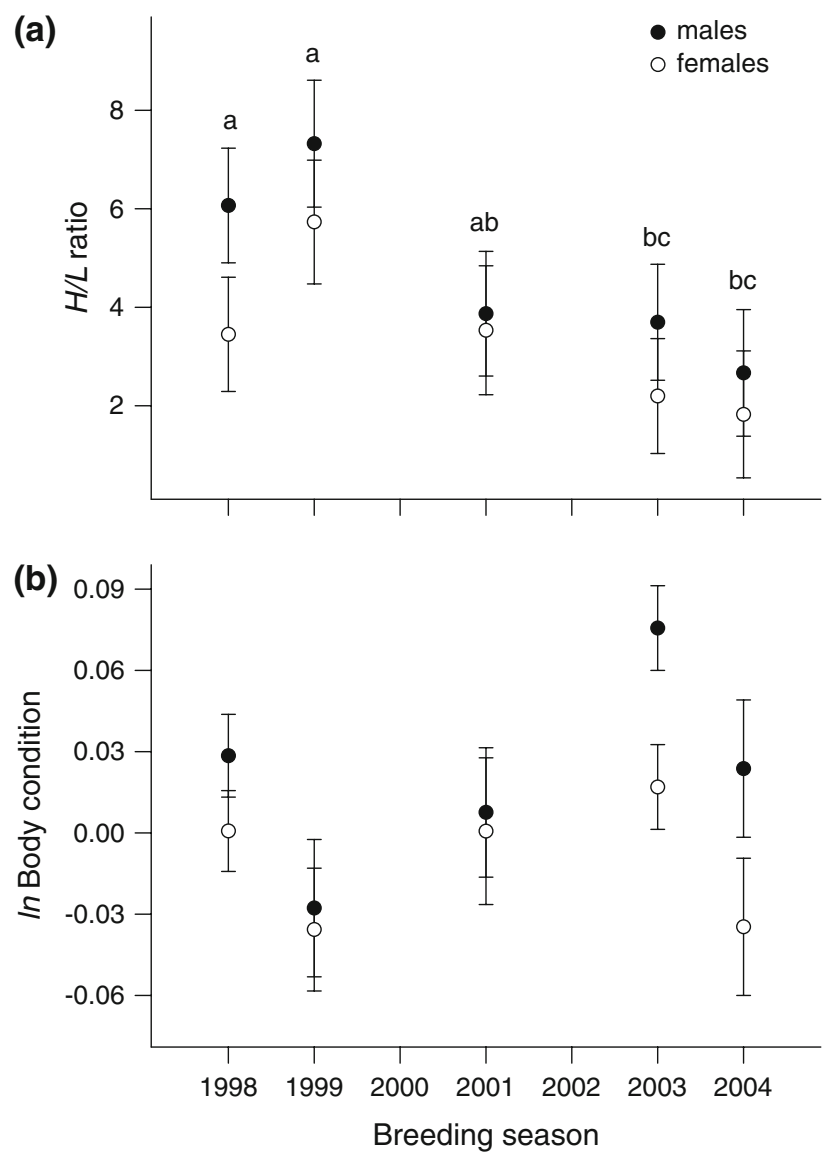

Fig. 1 Variation in (a) $H / L$ ratios and (b) $\ln$ body condition among breeding seasons plotted separately for male and female burrowing parrots. For $H / L$, homogeneous subsets are indicated, as obtained from multiple comparisons of estimated marginal means

$H / L$ ratios (Fig. 1, Table 1) and lower lymphocyte counts per 10,000 erythrocytes (Fig. 2) compared with females throughout the study period. For heterophil counts per
10,000 erythrocytes and the total abundance of leucocytes per 10,000 erythrocytes we found strong interaction patterns between variation among years and gender differences (Table 2, Figs. 1, 2). H/L ratios and heterophils per 10,000 erythrocytes negatively covaried with body condition (Table 2, Fig. 3). This was the true for both sexes, as apparent from the lack of a significant interaction term in the GLM.

\section{Discussion}

In this study, we investigated leucocyte profiles of adult burrowing parrots in the wild. As predicted, $H / L$ ratios were higher during the breeding season affected by a $\mathrm{La}$ Niña event (1998) compared with a breeding season affected by an El Niño event (2004). However, they were highest in 1999, during the breeding season following a $\mathrm{La}$ Niña event. Also as predicted, $H / L$ ratios were negatively correlated with individual body condition. In addition, we found significant gender differences in leucocyte values and relatively high $H / L$ values in burrowing parrots compared with other groups, which are likely to represent an inherent variation in immune physiology, rather than stress-related modulations.

Heterophilic profiles

In most of the adult burrowing parrots, heterophil numbers exceeded those of lymphocytes. This resulted in remarkably high mean $H / L$ ratios for both males and females (Table 1). Our results differ from previously published data on captive burrowing parrots $(H / L<1$; Polo et al. 1998). Experiments with zebra finches have shown that captivity can cause a significant and rapid decrease in $H / L$ ratios (Ewenson et al. 2001). This might 
(a)

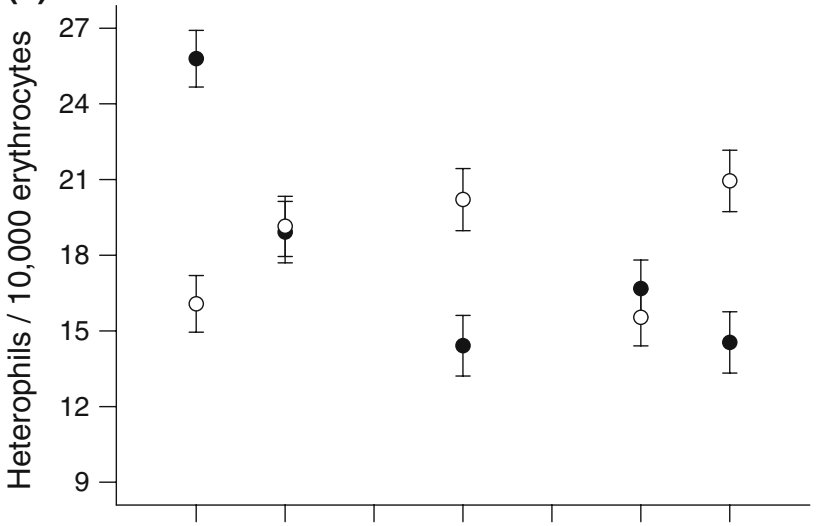

(b)

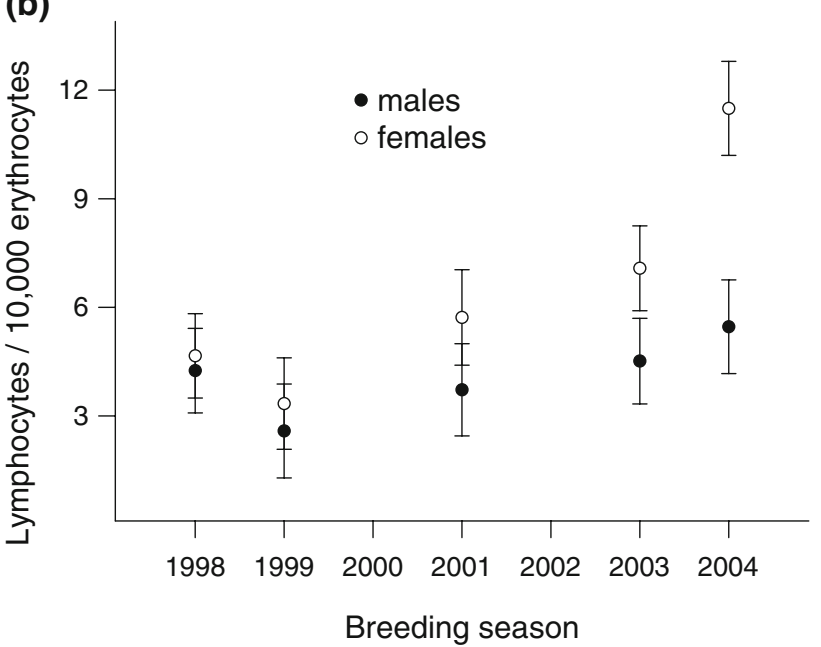

Fig. 2 Variation in (a) heterophils per 10,000 erythrocytes and (b) lymphocytes per 10,000 erythrocytes among breeding seasons, plotted separately for males and females (estimated marginal means obtained from GLMs were used and backtransformed to original scale)

explain the differences observed between our current data on wild individuals and those previously described from captive ones.

Psittaciformes often have heterophilic profiles (Joyner et al. 1992; Sheridan et al. 2004; Deem et al. 2005; Low et al. 2006; Masello et al. 2009) as here reported, in contrast with the lymphocytic profiles usually reported for Passeriformes (see review by Davis et al. 2008). Whether this general pattern reflects a differential investment in innate and acquired immunity (as, e.g., discussed in Masello et al. 2009) remains to be tested by direct manipulation of both the innate and acquired immune system (Davis et al. 2008). Heterophilic profiles could also reflect current challenges of the innate immune system, e.g. by bacterial, viral, or fungal infections (Hawkey and Dennett 1989; Davis et al. 2008). In any case, strong differences between phylogenetic groups emphasize the
Table 2 Sources of variation in leucocyte counts of burrowing parrots in NE Patagonia, Argentina

\begin{tabular}{lrrrrrr}
\hline Type III sum of squares & $d f$ & \multicolumn{1}{l}{$F$} & Sig. & $\eta^{2}$ & $\mathrm{t}$ \\
\hline (A) ln $H / L$ ratio & & & & & & \\
Year & 14.615 & 4 & 7.353 & $\mathbf{0 . 0 0 0}$ & 0.184 & \\
Gender & 5.917 & 1 & 11.908 & $\mathbf{0 . 0 0 1}$ & 0.084 & \\
Body condition & 6.293 & 1 & 12.664 & $\mathbf{0 . 0 0 1}$ & 0.089 & -3.559 \\
Error & 64.600 & 130 & & & &
\end{tabular}

(B) Heterophils/10,000 erythrocytes

$\begin{array}{lrrrrrr}\text { Year } & 1.283 & 4 & 1.058 & 0.380 & 0.032 & \\ \text { Gender } & 0.031 & 1 & 0.102 & 0.750 & 0.001 & \\ \text { Year } \times \text { Gender } & 3.251 & 4 & 2.681 & \mathbf{0 . 0 3 5} & 0.078 & \\ \text { Body condition } & 2.595 & 1 & 8.558 & \mathbf{0 . 0 0 4} & 0.064 & -2.925 \\ \text { Error } & 38.208 & 126 & & & & \end{array}$

(C) Lymphocytes/10,000 erythrocytes

$\begin{array}{lrrrrr}\text { Year } & 11.053 & 4 & 5.240 & \mathbf{0 . 0 0 1} & 0.138 \\ \text { Gender } & 3.012 & 1 & 5.712 & \mathbf{0 . 0 1 8} & 0.042 \\ \text { Error } & 69.087 & 131 & & & \end{array}$

(D) Total leucocytes $/ 10,000$ erythrocytes

$\begin{array}{lrrrrrr}\text { Year } & 0.660 & 4 & 0.629 & 0.642 & 0.020 & \\ \text { Gender } & 0.325 & 1 & 1.239 & 0.268 & 0.010 & \\ \text { Year } \times \text { Gender } & 2.763 & 4 & 2.636 & \mathbf{0 . 0 3 7} & 0.077 & \\ \text { Body condition } & 0.969 & 1 & 3.700 & 0.057 & 0.029 & -1.923 \\ \text { Error } & 33.019 & 126 & & & & \end{array}$

(E) Body condition

$\begin{array}{lrrrrr}\text { Year } & 0.087 & 4 & 4.273 & \mathbf{0 . 0 0 3} & 0.115 \\ \text { Gender } & 0.044 & 1 & 8.620 & \mathbf{0 . 0 0 4} & 0.062 \\ \text { Error } & 0.667 & 131 & & & \end{array}$

Results correspond to general linear models (GLMs) with $H / L$ ratios, heterophils/10,000 erythrocytes, lymphocytes/10,000 erythrocytes, and total leucocytes/10,000 erythrocytes as dependent variables, year and gender as fixed factors, and body condition as covariate. Additionally, effects of year and gender on body condition were tested in a separate GLM. For the GLMs with body condition as covariate, $t$-values are included to indicate the direction of the relationship. Data from five years were included: 1998, 22 males, 24 females; 1999, 8 males, 10 females; 2001, 9 males, 7 females; 2003, 21 males, 21 females; 2004, 8 males, 8 females. Significant $P$-values after Bonferroni correction are indicated in bold

importance of baseline information on sources of variation in haematological data, such as presented in this study.

Differences of leucocyte profiles between breeding seasons

North-eastern Patagonia was affected by a strong drought associated with a long La Niña event (1998-1999) during the 1998 breeding season (Oct. 1998-Feb. 1999). During that breeding season only $5 \%$ (1.5 $\mathrm{mm}$ in December) of the long-term mean rainfall was recorded. This in turn caused an important food shortage, and reduced the breeding success at the studied burrowing parrot colony (Masello 

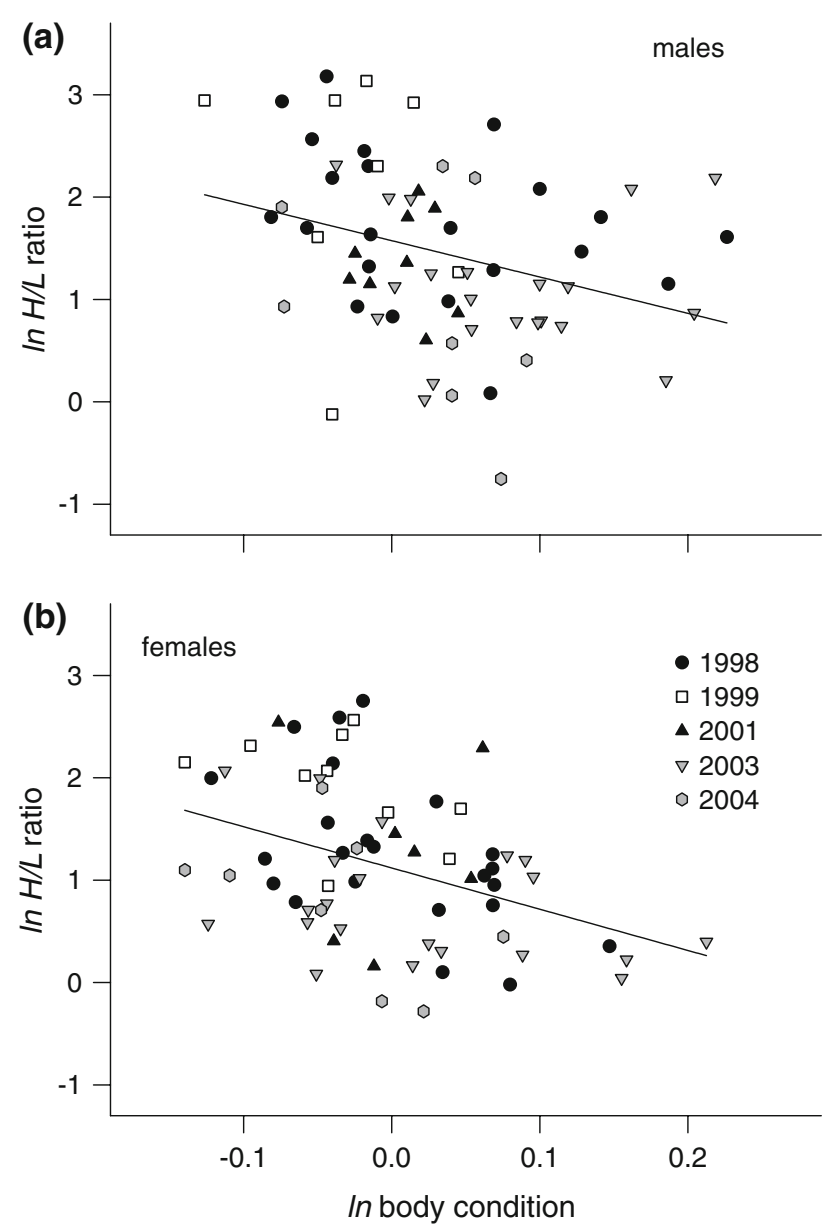

Fig. 3 Relationship among $\ln H / L$ ratios and $\ln$ body condition of (a) male and (b) female burrowing parrots during five breeding seasons

and Quillfeldt 2004). In contrast, during the 2004 breeding season (Nov. 2004-Jan. 2005), conditions associated with an El Niño event enhanced local precipitation $(76 \mathrm{~mm}$ in December, or $304 \%$ of the long-term average), which was the highest so far recorded during our research in NE Patagonia. As a consequence, in the 2004 breeding season burrowing parrots had the highest reported breeding success (Masello and Quillfeldt 2008). In accordance with this, adult birds showed increased $H / L$ ratios in the 1998 breeding season compared with that in 2004 (Fig. 1a). Thus, the droughts associated with the La Niña event not only affected nestling survival in burrowing parrots (Masello and Quillfeldt 2004), but also imposed physiological stress on the adults, reflected by increased $H / L$ ratios. However, the highest $H / L$ values, and lowest body condition, were recorded during the 1999 breeding season (Nov. 1999-Jan. 2000), a period of average rainfall in the region and intermediate reproductive success in this species (Masello and Quillfeldt 2004, 2008).

In a previous analysis, burrowing parrots responded to unfavourable conditions by maintaining their own body condition (adaptive mass regulation; Masello and Quillfeldt 2003). During the breeding season of 1998, adults at the study site had higher body mass and body condition, but reduced provisioning, than during years of average conditions (Masello and Quillfeldt 2003). This higher investment in own survival (and thus in future offspring) might explain why the highest $H / L$ ratios were not observed in 1998. Another possible explanation of higher body condition (and lower $H / L$ ratios) in an unfavourable year could be that only those birds in the best condition were breeding whereas birds in a worse state forego reproduction in harsh years. However, this is very unlikely as there was no significant difference in the proportion of active nests between the breeding season affected by La Niña (1998) and the breeding season during average precipitation conditions (1999; Masello and Quillfeldt 2004).

What, however, might have caused the peak in $H / L$ ratios in 1999, a breeding season of average precipitation conditions and high breeding success? Two explanations are possible. Breeding success and nestling growth mainly depends on food availability during nestling provisioning, and might therefore quickly and directly respond to changes in the resources. Physiological stress of adults, in contrast, might also outlast the actual adverse period, as the birds have to compensate for energy losses. In our case, despite the local favourable conditions during the 1999 breeding season, birds might not have fully recovered from the previous breeding season under La Niña-associated conditions, and might therefore have been more sensitive to the general demands of breeding. This is supported by the observed lowest body condition of birds in the 1999 breeding season (Fig. 1b). Second, leucocytes respond to disease condition, and adult birds might have suffered high infection rates causing increased stress and reduced body condition in 1999, without affecting breeding success and nestling growth. While burrowing parrots seem to lack blood and intestinal parasites (Masello et al. 2006), no data on fungal, bacterial, or viral infections are currently available.

Leucocytes, gender and body condition

The negative relationship between $H / L$ and body condition suggests a stress-relatedness of this ratio. This correlation seems to originate mostly from a relationship between condition and heterophils, rather than lymphocytes (Table 2).

While within-gender $H / L$ ratios are negatively related to body condition (Fig. 3), gender differences in $H / L$ are, in contrast, paralleling the gender differences in condition (Fig. 2): males had higher $H / L$ ratios and were in better body condition. Thus, the gender differences in $H / L$ seem not to be related to physiological stress but probably 
represent some inherent difference between the sexes in haematological characteristics and immunity. Heterophil abundances showed a much more complex pattern of variation among years and gender than lymphocytes (Fig. 1), suggesting that other factors are affecting the abundance of these cells, for example current immune challenges.

\section{Suggestions for further research}

Future studies could contribute to a more precise picture of the ecology of stress in burrowing parrots by collecting information, outside the breeding periods, about unknown wintering areas and migratory routes. Data on individual disease condition would be useful for a proper interpretation of relationships with environmental conditions. Information on non-breeding birds is necessary, because birds might selectively forego breeding periods depending on climate and own condition, possibly creating a bias in the sample of breeding birds. Analysing data of recaptured birds could help to evaluate the effects and importance of individual variation.

\section{Zusammenfassung}

Leukozyten bei im Freiland brütenden Felsensittichen

Cyanoliseus patagonus: Abhängigkeiten von

Brutzeiten, Geschlecht und individueller Kondition

Unter dem Einfluss von Stressoren können wildlebende Vögel die Investition in ihr Immunsystem verändern. Wir haben Leukozyten brütender Felsensittiche (Cyanoliseus patagonus) in Patagonien in fünf Brutperioden untersucht. Während der Studie traten globale Klimaereignisse mit Einfluss auf das Brutgebiet auf: ein starkes La Niña- und ein schwaches El Niño-Ereignis. Zwischen den Brutperioden wurden große Unterschiede im Verhältnis der Heterophilen zu Lymphozyten $(H / L)$ beobachtet, wobei höhere $H / L$ Quotienten unter den widrigen Umweltbedingungen von La Niña im Vergleich zu den im Studiengebiet günstigen Bedingungen von El Niño auftraten. Die höchsten $H / L$ Werte wurden jedoch in einer auf La Niña folgenden Brutperiode gefunden, möglicherweise verursacht durch längerfristige Auswirkungen der vorangehenden Klimasituation in Kombination mit anderen, z.B. biotischen Stressoren. Männchen zeigten höhere $H / L$ Werte als Weibchen und $H / L$ korrelierte negativ mit individueller Körperkondition.

Acknowledgments We wish to thank Ramón Conde, Adrián Pagnossin, Roberto Ure, María Luján Pagnossin, Mara Marchesan, Gert Dahms, Nora Lisnizer, María Laura Josens, Joanna Loughrey, and Mauricio Failla for their help in the fieldwork. This project was partially supported by the City Council of Viedma, Río Negro,
Argentina, and a grant from the state of Thuringia, Germany (Landesgraduiertenstipendium), a co-operation grant between the IB of the BMBF of Germany (ARG 99/020) and the Argentinean SECyT (AL/ A99-EXIII/003), a grant from the Deutsche Forschungsgemeinschaft (QU148-1 ff., Germany), a grant from the World Parrot Trust, and a grant from the Liz Claiborne Art Ortenberg Foundation and the Wildlife Conservation Society. This study was carried out with permission from the Dirección de Fauna de la Provincia de Río Negro, Argentina (Exp. no. 143089-DF-98).

Open Access This article is distributed under the terms of the Creative Commons Attribution Noncommercial License which permits any noncommercial use, distribution, and reproduction in any medium, provided the original author(s) and source are credited.

\section{References}

Davis AK (2005) Effect of handling time and repeated sampling on avian white blood cell counts. J Field Ornithol 76:334-338

Davis AK, Maney DL, Maerz JC (2008) The use of leukocyte profiles to measure stress in vertebrates: a review for ecologists. Funct Ecol 22:760-772

Deem SL, Noss AJ, Cuellar RL, Karesh WB (2005) Health evaluation of free-ranging and captive blue-fronted Amazon parrots (Amazona aestiva) in the Gran Chaco, Bolivia. J Zoo Wildl Med 36:598-605

Dein FJ (1986) Hematology. In: Harrison GJ, Harrison WR (eds) Clinical avian medicine and surgery. W. B. Saunders Company, Philadelphia, pp 174-191

Ewenson L, Zann RA, Flannery GR (2001) Body condition and immune response in wild Zebra Finches: effects of capture, confinement and captive-rearing. Naturwissenschaften 88:391394

Garamszegi LZ, Merino S, Török J, Eens M, Martínez J (2006) Indicators of physiological stress and the elaboration of sexual traits in the collared flycatcher. Behav Ecol 17:399-404

Gross WB, Siegel HS (1983) Evaluation of the heterophil/lymphocytes ratio as a measure of stress in chicken. Avian Dis 27:972979

Hawkey CM, Dennett PB (1989) A colour atlas of comparative veterinary haematology. Wolfe Medical Publications, Ipswich

Joyner KL, de Berger N, Lopez EH, Brice A, Nolan P (1992) Health parameters of wild psittacines in Guatemala: a preliminary report. Proc Assoc Avian Vet 1992:287-303

Karesh WB, del Campo A, Braselton WE, Puche H, Cook RA (1997) Health evaluation of free-ranging and hand-reared Macaws (Ara spp.) in Peru. J Zoo Wildl Med 28:368-377

Lessells CM, Boag PT (1987) Unrepeatable repeatabilities: a common mistake. Auk 104:116-121

Low M, Eason D, Elliott G, McInnes K, Paul-Murphy J (2006) Hematologic and biochemical reference ranges for the Kakapo (Strigops habroptilus): generation and interpretation in a fieldbased wildlife recovery program. J Avian Med Surg 20:80-88

Masello JF, Quillfeldt P (2003) Body size, body condition and ornamental feathers of Burrowing Parrots: variation between years and sexes, assortative mating and influences on breeding success. Emu 103:149-161

Masello JF, Quillfeldt P (2004) Consequences of La Niña phase of ENSO for the survival and growth of nestling Burrowing Parrots on the Atlantic coast of South America. Emu 104:337-346

Masello JF, Quillfeldt P (2008) Klimawandel und Brutverhalten: erfolgreich brüten in wechselhafter Umwelt? Eine Fallstudie am Felsensittich. Vogelwarte 46:302-303 
Masello JF, Choconi RG, Sehgal RNM, Tell L, Quillfeldt P (2006) Blood and intestinal parasites in wild Psittaciformes: a case study of Burrowing Parrots (Cyanoliseus patagonus). Ornitol Neotrop 17:515-529

Masello JF, Choconi RG, Helmer M, Kremberg T, Lubjuhn T, Quillfeldt P (2009) Do leucocytes reflect condition in nestling burrowing parrots (Cyanoliseus patagonus) in the wild? Comp Biochem Physiol A 152:176-181

Maxwell MH (1993) Avian blood leukocyte responses to stress. World's Poult Sci J 49:34-43

Merino S, Martínez J, Møller AP, Sanabria L, de Lope F, Pérez J, Rodríguez-Caabeiro F (1999) Phytohaemagglutinin injection assay and physiological stress in nestling House Martins. Anim Behav 58:219-222

Owen JC, Moore FR (2006) Seasonal differences in immunological condition of three species of thrushes. Condor 108:389-398

Paruelo JM, Beltrán AB, Jobbágy EG, Sala OE, Golluscio RA (1998) The climate of Patagonia: general patterns and controls on biotic processes. Ecol Austral 8:85-101

Polo FJ, Peinado VI, Viscor G, Palomeque J (1998) Hematologic and plasma chemistry values in captive psittacine birds. Avian Dis 42:523-535

Quillfeldt P, Ruiz G, Aguilar Rivera M, Masello JF (2008) Variability in leucocyte distributions and stress index in Thin-billed prions
Pachyptila belcheri during a poor season. Comp Biochem Physiol A 150:26-31

Renton K, Salinas-Melgoza A (2004) Climatic variability, nest predation, and reproductive output of Lilac-crowned Parrots (Amazona finschi) in tropical dry forest of Western Mexico. Auk 121:1214-1225

Ropelewski CF, Halpert MS (1987) Global and regional scale precipitation patterns associated with El Niño/Southern oscillation. Mon Wea Rev 115:1606-1626

Sheridan JA, Beissinger SR, Hughes CR (2004) Weak association between measures of health and reproductive success in Greenrumped Parrotlets (Forpus passerinus) in Venezuela. Auk 121:717-725

Siegel HS (1985) Immunological responses as indicators of stress. World's Poult Sci J 41:36-44

Snyder N, McGowan P, Gilardi J, Grajal A (2000) Parrots. Status Survey and Conservation Action Plan 2000-2004. IUCN, Gland, Switzerland and Cambridge, UK

Tompkins DM, Mitchell RA, Bryant DM (2006) Hybridization increases measures of innate and cell-mediated immunity in an endangered bird species. J Anim Ecol 75:559-564

Vleck CM, Vertalino N, Vleck D, Bucher TL (2000) Stress, corticosterone, and heterophil to lymphocyte ratios in free-living Adelie Penguins. Condor 102:392-400 